(5) $=\mathrm{e}$

\title{
Pengaruh Suhu pada Esterifikasi Amil Alkohol dengan Asam Asetat Menggunakan Asam Sulfat sebagai Katalisator
}

\author{
Muhammad Naufal Fakhry* dan Suprihastuti Sri Rahayu \\ Departemen Teknik Kimia, Fakultas Teknik, Universitas Gadjah Mada \\ Jl. Grafika No. 2 Kampus UGM, Yogyakarta, 55281 \\ *Alamat korespondensi: naufalfakhry@gmail.com
}

\begin{abstract}
A B S T RACT
Ester compounds are widely used as solvents, artificial aroma materials, and precursors of pharmaceutical ingredients. One of the ester compounds widely used in the chemical industry is amyl acetate. Amyl acetate can be synthesized by esterification of amyl alcohol and acetic acid, which is a liquid-liquid heterogeneous reaction. This study aims to study the kinetics of this particular reaction focusing on the effect of temperature. The catalyst used in this study was sulfuric acid. The mole ratio of acetic acid to amyl alcohol used was 2: 5. Reaction was run at constant temperature in a threeneck flask as a batch reactor. The acetic acid and sulfuric acid were first put into the reactor and heated while stirring. After reaching a certain temperature, the preheated amyl alcohol was added into the reactor. During reaction, the temperature was maintained at the desired temperature. The reactants and products involved in this reaction were immiscible. The product phases were separated and then the remaining acetic acid content in the water-soluble phase was analyzed by volumetric method. The study was carried out in 4 variations of temperature i.e. $70,80,90$, and $100^{\circ} \mathrm{C}$. The results of experimental data analysis showed that the reaction will be faster when the temperature is higher. The mass transfer from the acetic acid phase to the amyl alcohol phase increased with the increase of temperature. The value of the reaction rate constant, the overall mass transfer coefficient, and the Henry's constant were evaluated by the parameter fitting method using the MATLAB program. Based on the evaluation at the highest reaction temperature $100^{\circ} \mathrm{C}$, the rate constant was $0,0134 \mathrm{~mL}_{\mathrm{L}} \mathrm{mole}^{-2} \mathrm{~s}^{-1}$, the mass transfer coefficient was 0,3180 L s $\mathrm{s}^{-1}$, and the Henry's constant was $0,0174(\text { mole } / L)_{A}$ in phase II $/(\text { mole } / L)_{A}$ in phase I.
\end{abstract}

Keywords: esterification, immiscible, amyl acetate, mass transfer

\section{A B S T R A K}

Senyawa ester banyak dipakai sebagai solven, bahan aroma buatan, dan prekursor bahan-bahan farmasi. Salah satu senyawa ester yang banyak digunakan dalam industri kimia dalah amil asetat. Ester amil asetat dapat disintesis melalui reaksi esterifikasi dengan bahan baku amil alkohol dan asam asetat. Reaksi ini merupakan reaksi heterogen cair-cair. Penelitian ini bertujuan untuk mempelajari kinetika reaksi tersebut, terutama pengaruh variabel suhu. Untuk mempercepat laju reaksi ditambahkan asam sulfat. Perbandingan mol pereaksi asam asetat:amil alkohol yang digunakan sebesar 2:5. Reaksi dijalankan dalam reaktor batch dan suhu dijaga konstan. Reaktan dan katalisator dicampur dalam labu leher tiga. Asam asetat dan asam sulfat dituangkan ke dalam reaktor, dipanaskan dan diaduk sampai suhu tertentu. Selanjutnya amil alkohol yang telah dipanaskan sebelumnya hingga suhu tertentu dituangkan. Selama reaksi suhu dipertahankan konstan. Reaktan dan produk yang terlibat 
dalam reaksi ini berupa campuran immiscible. Produk yang terdiri dari dua fase dipisahkan antar fasenya kemudian fase yang larut dalam air dianalisis kadar asam asetat sisanya dengan metode volumetri. Reaksi dilakukan masing-masing pada suhu $70,80,90$, dan $100^{\circ} \mathrm{C}$. Hasil analisis menunjukkan bahwa reaksi akan semakin cepat apabila suhu semakin tinggi. Transfer massa dari fase asam asetat ke fase amil alkohol semakin besar pula dengan adanya kenaikan suhu. Nilai konstanta kecepatan reaksi, koefisien transfer massa overall, dan konstanta Henry dievaluasi dengan metode fitting parameter menggunakan program MATLAB. Berdasarkan evaluasi pada suhu reaksi tertinggi yaitu $100^{\circ} \mathrm{C}$ diperoleh nilai konstanta kecepatan reaksi sebesar $0,0134 \mathrm{~mL} \cdot \mathrm{mol}^{-2} \mathrm{~s}^{-1}$, koefisien transfer massa overall sebesar $0,318 \mathrm{~mL} \mathrm{~s}^{-1}$, dan konstanta Henry sebesar $0,0174(\mathrm{~mol} / \mathrm{L})_{\text {A di fase II }} /(\mathrm{mol} / \mathrm{L})_{\text {A di fase I. }}$.

Kata kunci: esterifikasi, immiscible, amil asetat, transfer massa

\section{Pendahuluan}

Esterifikasi merupakan reaksi untuk membentuk senyawa ester. Ester-ester organik banyak digunakan di industri, yaitu sebagai solven, bahan parfum, bahan aroma buatan, dan prekursor bahan-bahan farmasi. Salah satu senyawa ester yang banyak dipakai dalam industri adalah amil asetat. Amil asetat merupakan salah satu ester yang memiliki rumus kimia $\mathrm{CH}_{3} \mathrm{COOC}_{5} \mathrm{H}_{11}$. Ester ini banyak digunakan sebagai solven dalam industri pembuatan selulosa nitrat. Amil asetat dapat diproduksi dengan reaksi esterifikasi asam asetat dengan amil alkohol.

Reaksi esterifikasi merupakan reaksi yang berjalan lambat sehingga membutuhkan katalis untuk menunjang kecepatan reaksi. Maka dari itu banyak penelitian dilakukan untuk mempelajari kinetika reaksi, baik dengan katalis homogen maupun heterogen. Katalis homogen yang biasa digunakan dalam industri adalah asam sulfat. Ion $\mathrm{H}^{+}$dari asam sulfat sebagai asam kuat mendorong asam karboksilat untuk terprotonasi sehingga reaksi dapat terjadi. Oleh karena itu asam sulfat memiliki aktivitas yang lebih tinggi dibandingkan dengan katalis heterogen seperti resin atau zeolit.

Reaksi esterifikasi adalah reaksi bolak-balik sehingga konversi dibatasi oleh konversi kesetimbangan. Peneliti-peneliti sebelumnya seperti Leyes dan Othmer (1945) umumnya mengambil perbandingan komposisi pereaksi dengan jumlah alkohol berlebihan dengan maksud memperbesar konversi kesetimbangan. Untuk menggeser kesetimbangan ke arah produk, dilakukan berbagai cara, yaitu dengan menggunakan reaktan yang berlebih (excess), menghilangkan air dari campuran dengan menambahkan benzene sebagai cosolvent dan mendistilasi campuran azeotrop air dan benzene (Carey, 2000), serta mengatur suhu reaksi esterifikasi hingga kesetimbangan bergeser ke arah produk.

Berdasarkan penelitian yang telah dilakukan Swandana (2004) mengenai esterifikasi amil alkohol dengan asam asetat menggunakan asam sulfat sebagai katalisator, diperoleh hasil yang menunjukkan bahwa pada rentang suhu 69$112^{\circ} \mathrm{C}$, konversi yang dihasilkan mencapai 40 $67 \%$ dalam rentang waktu 1-6 jam. Pada penelitian tersebut digunakan perbandingan mol reaktan amil alkohol dengan asam asetat 1:1 untuk volume total reaktan sebesar $420 \mathrm{~mL}$ dan kecepatan pengaduk sebesar $240 \mathrm{rpm}$.

Untuk mempelajari kinetika reaksi esterifikasi pembuatan amil asetat ini digunakan katalis asam sulfat, sedangkan di antara variabel yang berpengaruh, penelitian ini mempelajari pengaruh suhu. Reaksi esterfikasi amil alkohol dengan asam asetat ini merupakan reaksi immiscible di mana reaktan tidak saling larut sehingga produk juga tidak saling larut. Oleh karena itu, pada penelitian ini juga akan dipelajari pengaruh suhu terhadap transfer massa antar reaktan.

Pada sistem heterogen cair-cair untuk amil alkohol dan asam asetat, dianggap hanya asam asetat yang berpindah ke fase amil alkohol, sedangkan transfer massa amil alkohol ke fase asam asetat diabaikan. Dengan asumsi tersebut, reaksi hanya terjadi di fase alkohol. Dan mekanisme reaksi dapat digambarkan dengan teori 2 lapisan yang digabung, sehingga diperoleh 
persamaan-persamaan sebagai berikut (Sediawan dan Prasetya, 1997):

Perubahan konsentrasi asam asetat $\left(x_{A}, \mathrm{~mol} / \mathrm{L}\right)$ di fase asam asetat (fase I) terhadap waktu dinyatakan dalam Persamaan (1) dengan $t=$ waktu $(s), V_{I}=$ volume cairan fase I, $V_{I I}=$ volume cairan fase II, $x_{A} *=$ konsentrasi jenuh asam asetat pada kesetimbangan (mol/L), dan $K_{X A} . a=$ koefisien transfer massa overall $\left(\mathrm{mL} / \mathrm{s}^{-1}\right)$

$$
\frac{d x_{A}}{d t}=-\frac{\left(V_{I}+V_{I I}\right)}{V_{I}} K_{x_{A}} \cdot a\left(x_{A}-x_{A}^{*}\right)
$$

Nilai $x_{A} *$ dikorelasikan dengan nilai konsentrasi asam asetat di fase amil alkohol $\left(y_{A}\right.$, mol/L) sebagai Persamaan (1b), dengan $H_{A}=$ konstanta Henry $(\mathrm{mol} / \mathrm{L})_{\text {A di fase II }} /(\mathrm{mol} / \mathrm{L})_{\text {A di fase I }}$.

$$
y_{A}=H_{A} x_{A}^{*}
$$

Perubahan konsentrasi asam asetat $\left(y_{A}, \mathrm{~mol} / \mathrm{L}\right)$ di fase amil alkohol (fase II) terhadap waktu dinyatakan dalam Persamaan (2) dengan $t=$ waktu $(s), V_{I}=$ volume cairan fase I, $V_{I I}=$ volume cairan fase II, $y_{B}=$ konsentrasi amil alkohol $(\mathrm{mol} / \mathrm{L})$, dan $\mathrm{k}_{\mathrm{II}}=$ konstanta kecepatan reaksi $\left(\mathrm{mLmol}^{-2} \mathrm{~s}^{-1}\right)$.

$\frac{d y_{A}}{d t}=\frac{\left(V_{I}+V_{I I}\right)}{V_{I}} K_{x_{A}} \cdot a\left(x_{A}-x_{A}^{*}\right)-k_{I I} \cdot y_{A} \cdot y_{B}$

Perubahan konsentrasi amil alkohol ( $\mathrm{y}_{\mathrm{B}}$, mol/L) di fase amil alkohol (fase II) terhadap waktu dinyatakan dalam Persamaan (3).

$$
\frac{d y_{B}}{d t}=-k_{I I} \cdot y_{A} \cdot y_{B}
$$

Persamaan (1), (2), dan (3) diselesaikan secara simultan menggunakan program MATLAB dengan kondisi batas pada saat $t=0 ; x_{A}=x_{A 0} ; y_{A}$ $=0 ; y_{B}=y_{B 0}$. Dari penyelesaian persamaan yang memberikan kesesuaian terbaik dengan data eksperimen, diperoleh nilai konstanta-konstanta pada kecepatan transfer massa dan kecepatan reaksi.

\section{Metode Penelitian}

\subsection{Bahan penelitian}

Asam asetat $\left(\mathrm{CH}_{3} \mathrm{COOH}\right)$ glasial yang rapat massanya $=1,049 \mathrm{gram} / \mathrm{cm}^{3}$. Amil Alkohol $\left(\mathrm{C}_{5} \mathrm{H}_{11} \mathrm{OH}\right)$ dengan kadar $99 \%$ dan rapat massa
$0,817 \mathrm{gram} / \mathrm{cm}^{3}$, dan asam sulfat $98 \%\left(\mathrm{H}_{2} \mathrm{SO}_{4}\right)$ dengan rapat massa $1,840 \mathrm{gram} / \mathrm{cm}^{3}$.

\subsection{Alat penelitian}

Esterifikasi dijalankan dalam labu leher tiga sebagaimana diilustrasikan pada Gambar 1.

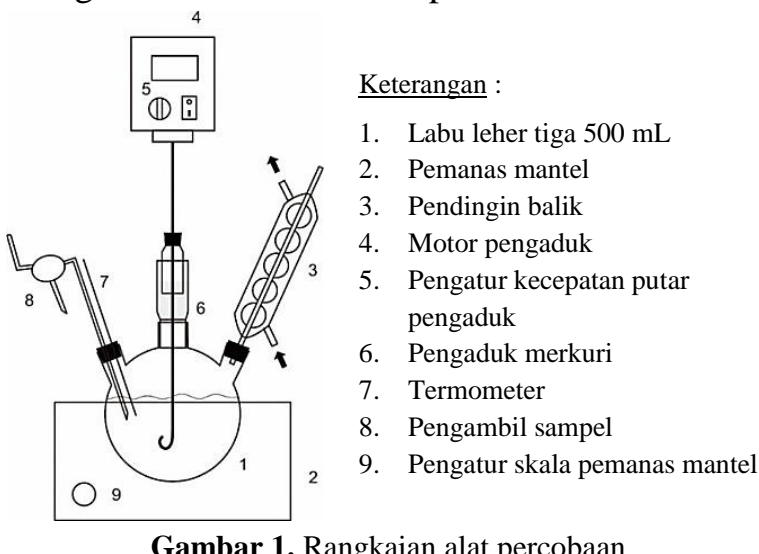

\subsection{Cara penelitian}

Sebanyak $72 \mathrm{~mL}$ asam asetat dan sebanyak $2 \%$ vol asam sulfat dimasukkan ke dalam labu leher tiga kemudian pengaduk dan pemanas mantel dinyalakan. Amil alkohol sebanyak 378 $\mathrm{mL}$ (sehingga rasio mol asam asetat:alkohol = 2:5) dipanaskan terpisah, menggunakan kompor listrik. Ketika amil alkohol mencapai suhu $90^{\circ} \mathrm{C}$, dimasukkan ke dalam campuran asam asetat dan asam sulfat di labu leher tiga yang suhunya sudah mencapai $90^{\circ} \mathrm{C}$. Selanjutnya sampel diambil. Pengambilan sampel dilakukan setiap rentang waktu tertentu. Sampel kemudian dianalisis dengan titrasi menggunakan $\mathrm{NaOH} 0,1 \mathrm{~N}$ dan indikator pp. Percobaan dilakukan juga pada suhu 70,80 , dan $100^{\circ} \mathrm{C}$.

\subsection{Analisis Data}

\subsubsection{Perhitungan Konversi}

Konversi asam asetat dihitung dengan Persamaan (4).

$$
X_{A}=\frac{N_{A, t=0}-N_{A, t=t}}{N_{A, t=0}} \times 100 \%
$$

dengan $X_{A}=$ Konversi asam asetat $(\%), N_{A, \mathrm{t}=0}=$ Normalitas asam pada saat $t=0(\mathrm{mg} \mathrm{ek} / \mathrm{mL})$, dan $N_{A, \mathrm{t}=\mathrm{t}}=$ Normalitas asam pada saat $t=\mathrm{t}(\mathrm{mg}$ $\mathrm{ek} / \mathrm{mL})$. Normalitas asam dihitung dengan mengukur volume larutan $\mathrm{NaOH}$ standar yang 
dibutuhkan untuk titrasi asam dalam larutan sampel.

\subsubsection{Penentuan Konstanta Laju Reaksi $(k)$, Konstanta Henry $\left(H_{A}\right)$ dan Koefisien Transfer Massa Overall $\left(K x_{A}\right)$}

Dengan program MATLAB menggunakan fitting parameter methods, koefisien-koefien pada Persamaan (1a), (1b), (2) dan (3), yaitu konstanta laju reaksi, konstanta Henry dan koefisien transfer massa overall dapat dihitung.

\section{Hasil dan Pembahasan}

Salah satu faktor yang mempengaruhi laju reaksi adalah suhu. Suhu yang lebih tinggi meningkatkan konstanta laju reaksi. Pada sistem reaksi heterogen cair-cair, suhu juga mempengaruhi koefisien transfer massa dan konstanta Henry. Oleh karena itu, untuk mengetahui hubungan suhu dengan masingmasing konstanta dilakukan analisis terhadap data perubahan konsentrasi (normalitas) asam asetat terhadap waktu yang diperoleh dari reaksi esterifikasi amil alkohol dengan asam asetat menggunakan asam sulfat sebagai katalisator.

Pada Tabel 1 ditunjukkan bahwa banyaknya asam asetat yang terkonversi semakin meningkat seiring dengan kenaikan suhu reaksi. Konversi tertinggi dicapai pada suhu reaksi $100^{\circ} \mathrm{C}$. Hal ini mengindikasikan bahwa kecepatan reaksi akan semakin bertambah seiring dengan kenaikan suhu reaksi.

Tabel 1. Konversi asam asetat dengan rasio mol asam asetat:amil alkohol=2:5, N=530 rpm, dan $C k$ $2 \%$ vol

\begin{tabular}{ccccc}
\hline Waktu, & \multicolumn{4}{c}{ Konversi pada suhu, ${ }^{\circ} \mathrm{C}$} \\
\cline { 2 - 5 } menit & 70 & 80 & 90 & 100 \\
\hline 0 & 0,0000 & 0,0000 & 0,0000 & 0,0000 \\
5 & 0,0066 & 0,0490 & 0,0319 & 0,0360 \\
10 & 0,0182 & 0,0695 & 0,0574 & 0,0854 \\
15 & 0,0430 & 0,0742 & 0,0897 & 0,1375 \\
30 & 0,0496 & 0,0758 & 0,1440 & 0,1977 \\
60 & 0,0545 & 0,0869 & 0,1780 & 0,2223 \\
90 & 0,0612 & 0,0900 & 0,1797 & 0,2485 \\
120 & 0,0711 & 0,1027 & 0,1950 & 0,2539 \\
\hline
\end{tabular}

Hasil perhitungan pada Tabel 1 dalam bentuk grafik disajikan pada Gambar 2.

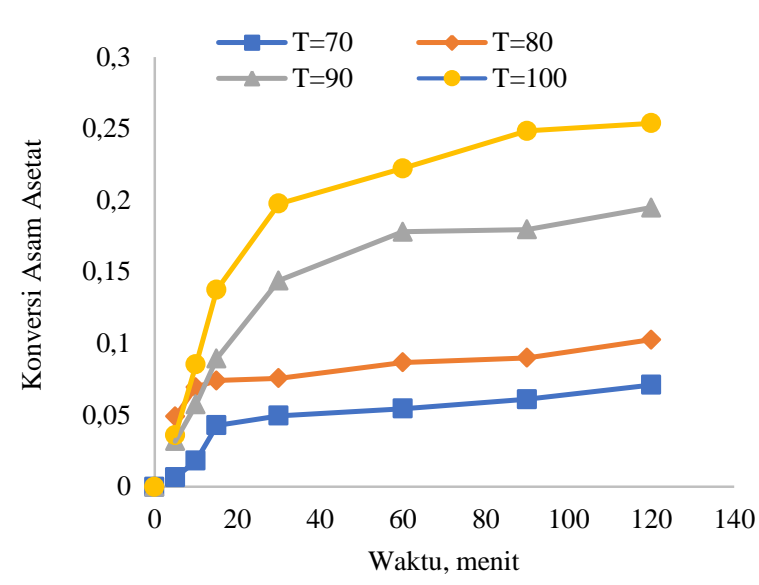

Gambar 2. Hubungan antara konversi asam asetat terhadap waktu

Berdasarkan Tabel 1 maupun Gambar 2 dapat dilihat bahwa konversi asam asetat meningkat seiring dengan berjalannya waktu. Selain itu, dapat dilihat bahwa perubahan kenaikan konversi asam asetat juga mengalami penurunan seiring berjalannya waktu. Hal ini disebabkan karena jumlah asam asetat yang ada pada reaktan semakin sedikit jumlahnya sehingga kenaikan konversi menjadi relatif tidak signifikan dibandingkan dengan sebelumnya.

Pengaruh suhu terhadap konversi asam asetat dapat dilihat juga pada Gambar 2. Konversi semakin meningkat seiring dengan kenaikan suhu. Hal ini disebabkan oleh pengaruh suhu pada energi internal molekul, sehingga pada suhu yang semakin tinggi molekul-molekul dalam reaktor akan bergerak semakin cepat dan intensitas tumbukan semakin tinggi. Akibatnya, reaksi dapat berjalan dengan lebih cepat. Namun, kenaikan suhu ini tidak selamanya akan meningkatkan konversi asam asetat dikarenakan reaksi esterifikasi ini merupakan reaksi eksotermis. Terdapat titik optimum dimana kenaikan suhu justru menurunkan kesetimbangan, sehingga tidak meningkatkan konversi asam asetat.

Terjadinya kenaikan kecepatan reaksi juga mengindikasi bahwa nilai konstanta-kontanta yang terlibat dalam proses juga mengalami kenaikan. Konstanta-konstanta itu adalah konstanta kecepatan reaksi, koefisien transfer massa, dan konstanta Henry. Untuk memperoleh nilai ketiga konstanta tersebut dilakukan 
parameter fitting dengan program MATLAB terhadap data percobaan pada setiap suhu.

Berikut disajikan grafik hubungan antara konsentrasi asam asetat dengan waktu hasil percobaan dan hasil parameter fitting.

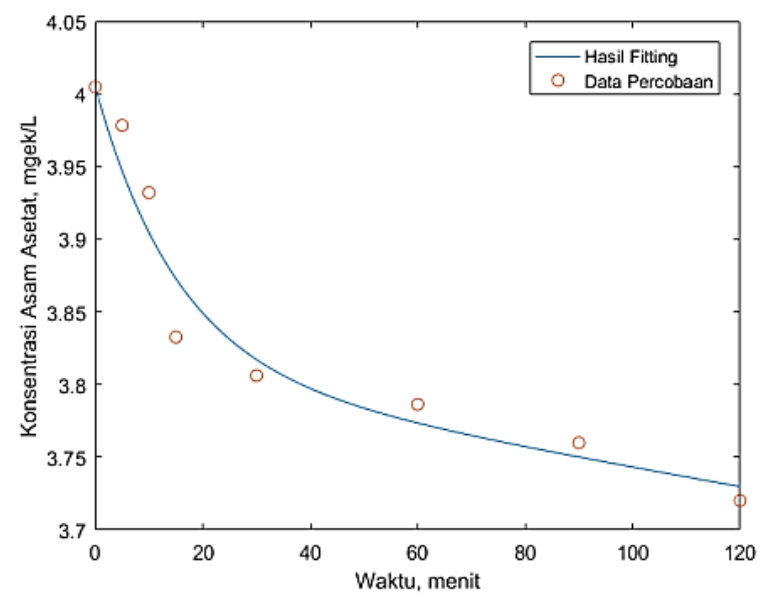

Gambar 3. Hasil fitting untuk esterifikasi amil alkohol dengan asam asetat pada suhu $70^{\circ} \mathrm{C}$

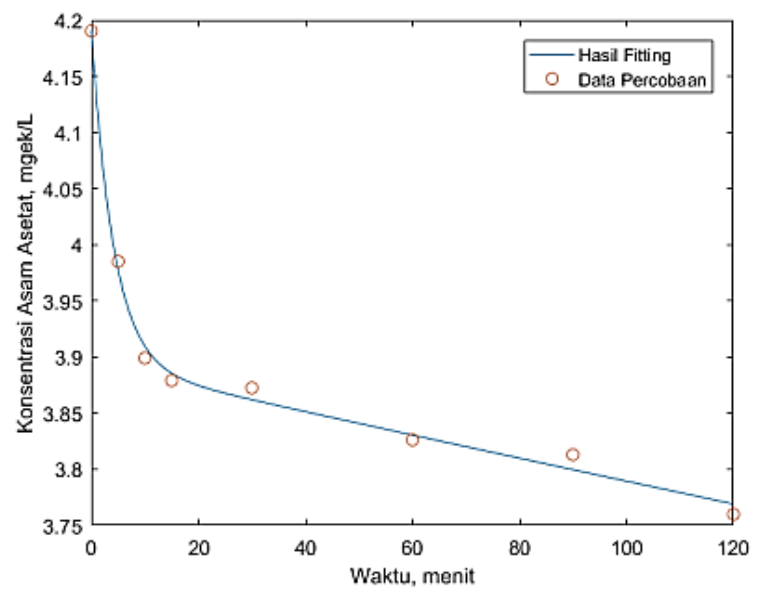

Gambar 4. Hasil fitting untuk esterifikasi amil alkohol dengan asam asetat pada suhu $80^{\circ} \mathrm{C}$

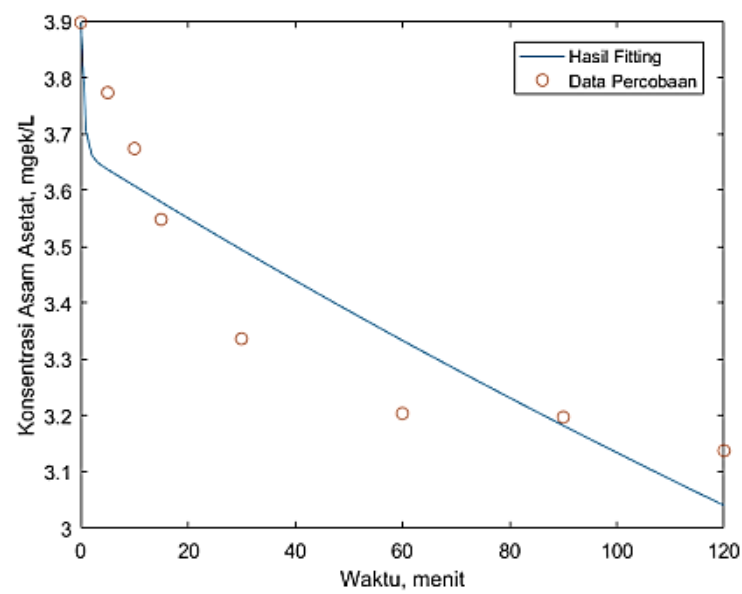

Gambar 5. Hasil fitting untuk esterifikasi amil alkohol dengan asam asetat pada suhu $90^{\circ} \mathrm{C}$

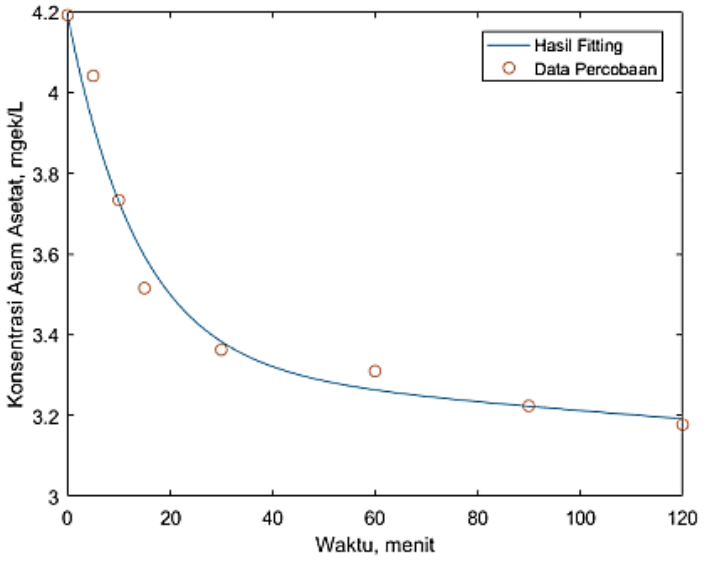

Gambar 6. Hasil fitting untuk esterifikasi amil alkohol dengan asam asetat pada suhu $100^{\circ} \mathrm{C}$

Hasil fiiting pada Gambar 3, 4, 5 dan 6, masing-masing diperoleh dengan SSE sebesar 0,0038; 0,0006; 0,0751; dan 0,1640. Hasil dari parameter fitting menunjukkan bahwa konsentrasi asam asetat semakin turun seiring berjalannya waktu. Hal ini disebabkan karena asam asetat berpindah dari fase I ke fase II kemudian bereaksi dengan amil alkohol di fase II.

Adapun konstanta kecepatan reaksi $(k)$, koefisien transfer massa $\left(K_{X A}\right)$, dan konstanta Henry $\left(H_{A}\right)$ pada setiap suhu percobaan tersaji pada Tabel 2.

Tabel 2. Hasil parameter fitting

\begin{tabular}{ccccc}
\hline Waktu, & \multicolumn{4}{c}{ Konversi pada suhu, ${ }^{\circ} \mathrm{C}$} \\
\cline { 2 - 5 } menit & 70 & 80 & 90 & 100 \\
\hline 0 & 0,0000 & 0,0000 & 0,0000 & 0,0000 \\
5 & 0,0066 & 0,0490 & 0,0319 & 0,0360 \\
10 & 0,0182 & 0,0695 & 0,0574 & 0,0854 \\
15 & 0,0430 & 0,0742 & 0,0897 & 0,1375 \\
30 & 0,0496 & 0,0758 & 0,1440 & 0,1977 \\
60 & 0,0545 & 0,0869 & 0,1780 & 0,2223 \\
90 & 0,0612 & 0,0900 & 0,1797 & 0,2485 \\
120 & 0,0711 & 0,1027 & 0,1950 & 0,2539 \\
\hline
\end{tabular}

Tabel 2 memperlihatkan bahwa konstanta kecepatan reaksi mengalami kenaikan seiring dengan kenaikan suhu reaksi. Hal ini sesuai dengan persamaan Arrhenius pada Persamaan (5).

$$
k=k_{o} \exp \left(-\frac{E}{R T}\right)
$$

dengan $k=$ konstanta kecepatan reaksi $\left(\mathrm{mL} \cdot \mathrm{mol}^{-2} \mathrm{~s}^{-}\right.$ $\left.{ }^{1}\right)$ pada suhu $T(\mathrm{~K}), k_{o}=$ konstanta tumbukan 
$\left(\mathrm{mL} \cdot \mathrm{mol}^{-2} \mathrm{~s}^{-1}\right), \quad E=$ energi aktivasi $(\mathrm{J} / \mathrm{mol}), \quad R=$ konstanta gas universal $(\mathrm{J} / \mathrm{mol} / \mathrm{K})$, dan $T=$ suhu (K). Untuk hasil penelitian ini, hubungan konstanta kecepatan reaksi dengan suhu dinyatakan dengan Persamaan (6) atau dalam bentuk lain pada Persamaan (7) dengan kesalahan relatif rata-rata sebesar $38,44 \%$.

$$
\begin{aligned}
& \ln \left(\frac{k}{8161945735}\right)=-\frac{83619,9194}{T} \\
& k=8161945735 \exp \left(-\frac{83619,9194}{T}\right)
\end{aligned}
$$

Koefisien transfer massa overall juga mengalami kenaikan seiring dengan kenaikan suhu reaksi. Hal ini disebabkan pada suhu yang lebih tinggi, viskositas cairan akan berkurang. Viskositas yang lebih rendah mengakibatkan bilangan Re meningkat sehingga tebal lapisan antar fase menjadi lebih tipis. Semakin tipis lapisan film antar fase, berarti semakin kecil tahanan transfer massa atau semakin tinggi koefisien transfer massa dari satu fase ke fase lain. Semakin tinggi suhu, konstanta Henry $\left(H_{A}\right)$ juga semakin tinggi. Apabila kenaikan $\mathrm{H}_{\mathrm{A}}$ akibat kenaikan suhu dibuat grafik, diperoleh garis lurus ln $H_{A}$ terhadap $1 / T$, sebagaimana dinyatakan dengan Persamaan (8) atau Persamaan (9) dengan kesalahan relatif rata-rata sebesar 5,15\%.

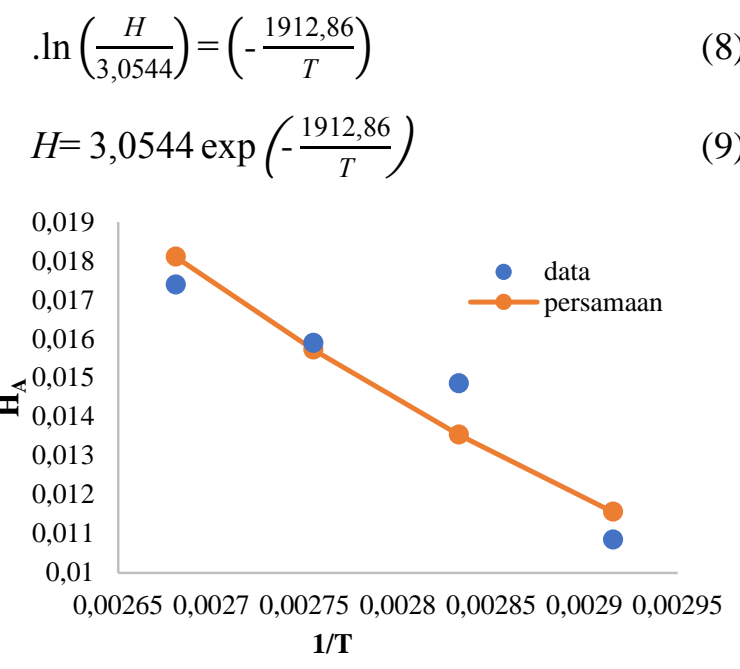

Gambar 7. Grafik hubungan antara $H_{A}$ terhadap $1 / T$
Gambar 7 memperlihatkan bahwa $H_{A}$ berbanding terbalik dengan $1 / T$, yang berarti semakin tinggi suhu, nilai $H_{A}$ semakin tinggi. Hal ini karena kelarutan zat dalam suatu cairan semakin tinggi oleh suhu yang semakin tinggi.

\section{Kesimpulan}

Dari penelitian ini dapat disimpulkan:

a. Esterifikasi amil alkohol dengan asam asetat pada perbandingan mol alkohol:asam asetat= 2:5 bisa dianggap berlangsung di fase alkohol saja.

b. Persamaan kecepatan reaksi searah order satu terhadap konsentrasi asam di fase alkohol dan order satu terhadap konsentrasi alkohol.

c. Konstanta kecepatan reaksi, koefisien transfer massa dan konstanta Henry masing-masing meningkat seiring dengan naiknya suhu.

\section{Daftar Pustaka}

Carey, 2000, "Organic Chemistry", $4^{\text {th }}$ Ed., pp.593, McGraw Hill Company lnc, New York.

Leyes, C. E., and Othmer, D. F., 1945, "Esterification of Butanol and Acetic Acid", Ind. Eng. Chem., 37, 968-977.

Sediawan, W.B. dan Prasetya, A., 1997, "Pemodelan Matematis dan Penyelesaian Numeris dalam Teknik Kimia dengan Pemrograman Bahasa Basic dan Fortran", ANDI Offset, Yogyakarta.

Swandana, B., 2004, "Esterifikasi Amil Alkohol dengan Asam Asetat (Pengaruh Suhu dan Konsentrasi Asam Sulfat)", Laporan Penelitian, Jurusan Teknik Kimia Fakultas Teknik Universitas Gadjah Mada, Yogyakarta. 